\title{
DARK TRIAD OF CROATIAN MANAGEMENT STUDENTS
}

\section{Bogdanovic, M., Cingula, D.}

This paper researches the so-called "dark triad" personality traits of management student populations, because of their potential to generate dysfunctional organizational behavior and processes. Namely, the dark triad with characteristics such as lack of empathy, willingness to manipulate others (for self-betterment), antagonism, and belief in one's own superiority can represent a real organizational threat. The goal of this paper is to stimulate thinking and discussion around this issue. The paper is based on questionnaire measurement that adopts the standardized short dark triad measurement instrument of Jones and Paulhus (2012) who measure the scales of Machiavellianism (9 items), narcissism (9 items) and psychopathy (9 items). The sample included 150 students of professional management studies at the Faculty of Economics, University of Split in Croatia. Results of the Croatian students are compared with the results of 387 students in Canada. The results suggest significant statistical differences in the "dark triad" variables between the Canadian and Croatian samples. The practical implications of this paper are in raising awareness and stimulating the thinking of managers around the potential of the "dark triad" traits of engaged human resources to create organizational crisis, and to make preventive and responsive actions to manage the "toxic triad" threat.

Keywords: Dark triad; Machiavellianism; narcissism; psychopathy; human resource management; organizational management; organizational pathology; organizational culture/climate.

JEL classification: M12, M5.

\section{Introduction}

In reality there is no organization that doesn't embody some kind of pathology (Hawley according to Lucic, 2013). This organizational pathology arises as a result of negative workplace behavior whose source is mostly in personal traits. Namely, the strongest predictor of an employee's behavior is his/her personality. So, personal traits such as integrity, authenticity, and optimism support positive behavior and positive outcomes, while negative personal traits are associated with negative workplace behaviors $\left(\mathrm{O}^{\prime}\right.$ Boyle et al., 2012). Negative or counterproductive work behaviors like theft, leader derailment, organizational politicking, mobbing, manipulation, sadism, etc. can have deleterious consequences for organizations in terms of organizational outputs such as performance, profit, and reputation. A meta-analysis of 43907 articles published about dark triad individuals in the workplace between 1951 and 2011 revealed that job performance was negatively related to Machiavellianism and psychopathy, and the possession of all three dark triad traits in employees was moderately related to bad productivity in the workplace (O'Boyle et al., 2011). Also individual studies found that narcissists in positions of power often engage in unethical behavior, psychopaths are a detriment to a company's productivity and are poor at cooperating with colleagues, and Machiavellians are abusive and

1 An earlier version of this paper was presented at the 7th International Conference at the School of Economics and Business in Sarajevo, Sarajevo, 13th-14th October 2014, Bosnia and Herzegovina. 
manipulative within the workplace and have demonstrated a diminished organizational commitment and poor supervisory responsibility (Black, 2013). Psychopathy, narcissism and Machiavellianism are three personality types which, in isolation, are bad enough, but in combination are utterly toxic. The dark triad is the set of three personality constructs that are considered to be socially aversive: subclinical psychopathy, Machiavellianism, and subclinical narcissism (Paulhus and Williams, 2002), so the dark triad is the term used to describe the combination of these three dark traits (Plumridge, 2013).

The dark triad consists of the three above-mentioned personality constructs: Machiavellianism, narcissism, and psychopathy. They can be characterized by a lack of empathy, a willingness to manipulate others (for self-betterment), antagonism, and a belief in one's own superiority (Paulhus and Williams, 2002). In such cases, they are considered to be especially harmful to the organization given the positional power of the individuals concerned and are typified by a "systematic and repeated behavior by a leader, supervisor or manager that violates the legitimate interest of the organization by undermining and/or sabotaging the organization's goals, tasks, resources, and effectiveness and/or the motivation, well-being or job satisfaction of subordinates" (Einarsen et al., 2007).

A bad, toxic or pathological organizational situation is caused by the employees; it is real and it is dangerous, especially if it is present in management or business leadership. In fact, $1 \%$ of normal people could be classified as psychopaths, rising to $4 \%$ in CEOs and business leaders, and 15-25\% of male offenders in federal correctional settings (Black, 2013; Yatzeck, 2012). In 2008, it was estimated that $6.2 \%$ of the population met the DSM-IV-TR criteria for narcissism (Black, 2013). What do these three toxic personality traits represent?

Machiavellianism indicates a manipulative personality. Machiavellians overtly manipulate and exploit people for their benefit. Machiavellians have cynical disregard for morality and engage in deception. They are skilled in negotiating and enjoy combat. They are good in forming political alliances, influencing others for their own gain, using flattery or deceit; if necessary, they use subtle skills to gain influence. But they can also be charismatic leaders and forceful negotiators. They can be creative because they often enjoy testing limits. Narcissism characterizes individuals who want to become the center of attention, seek prestige, who are characterized by grandiosity, entitlement, dominance, superiority and status with egotism that knows no bounds. They use appearance, ingratiating tactics, and phony compliments to get what they want. They are often skilled at making a good first impression, and people who can engagingly tell stories and impress others. Because of this behavior, they are at least initially respected and put in positions of authority and command by others. Psychopathy indicates an antisocial personality which is impulsive, thrills seeking, aggressive, tends towards antagonism and lacks remorse and empathy. Often these personalities are seen as hostile, harsh or arrogant; they can also be sadistic. They think rules don't apply to them. But they get their way through their superficial charming manner but also they tend to think creatively, test the limits and also are skilled as manipulators (forming political alliances). They tend to focus on short-terms benefits for themselves rather than long-term results for their organization (Malnick, 2013; Plumridge, 2013; Jonason et al., 2012; Jones and Paulhus, 2012; O'Boyle et al., 2012; Yatzeck, 2012).

All three constructs of the dark triad are high in striving for autonomy and superiority (agency) and low in connecting with and helping others (communion), and all three 
are high in ruthless self-advancement (Zuroff et al., 2010). Psychopaths score high on the impulsivity dimension; narcissism stands apart on the axis of superior identity (i.e. self-enhancement). For narcissism, the strongest associations are with low modesty and low straightforwardness, whereas psychopathy associations are strongest with low deliberation and low dutifulness. The strongest correlates of narcissism are achievement-striving and competence, whereas the strongest correlates of psychopathy are low dutifulness and low deliberation (Furnham, Richardson, Paulhus, 2013, p. 203-204). Further, all three dark triad constructs are positively correlated with lying, dominance and sadism (Bradlee and Emmons, 1992; Chabrol et al., 2009). Managers and other employees who score high on the dark triad (toxic employers) use hard (e.g. threats) and soft tactics (e.g. offering compliments or joking/kidding) to manipulate the person and the situation (Jonason et al., 2012). Namely, psychopathy in a work setting was related to the use of charm and coercion, Machiavellianism was related to the use of charm and seduction, and narcissism was related to invoking feelings of responsibility in others. Specifically, psychopaths and Machiavellians use direct and hard manipulation such as the use of threats, whereas narcissist and some Machiavellians employ softer methods of exploitation such as using compliments to ingratiate themselves with their fellow employees and then asking for "favors" (Black, 2013). Whereas narcissist claim to use soft manipulation tactics, psychopaths choose hard tactics, and machiavellists are the most flexible and use both soft and hard tactics. The dark triad scheme is presented in Figure 1.

\section{Figure 1 | Picture of the Dark Triad}

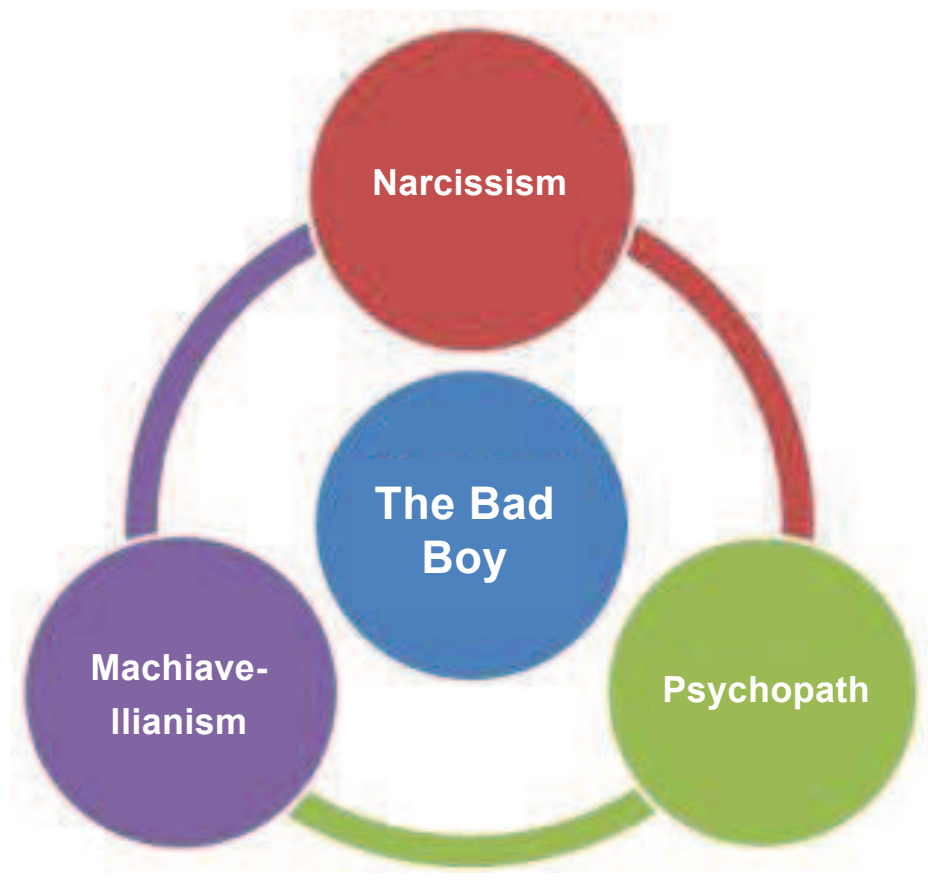

Source: Yatzeck (2012). 
According to Furnham (2010), three interrelated features of the dark side are:

1. Arrogance, self-centeredness, self-enhancement;

2. Duplicitousness, cynism, manipulativeness;

3. Emotionally cold, impulsive thrill-seeking and frequently engage in illegal, dangerous, anti-social behavior.

Dark side managers cheat and lie; they plagiarize and are known for their social deviance, but it is usually never extreme enough to warrant either imprisonment or even dismissal (Furnham, 2010). When organizations have manager(s) who score high on combined psychopathic, Machiavellian and narcissistic tendencies, it can be recognized by the following behaviors (Malnick, 2013):

1. They tend to exploit and trick others for self-advancement.

2. They have used lies and deception to get their way.

3. They have used ingratiation to get their way.

4. They tend to manipulate other for selfish reasons.

5. They tend not to feel regretful and apologetic after having done wrong.

6. They tend not to worry about whether their behavior is ethical.

7. They tend to be lacking in empathy and crassly unaware of the distress they can cause others.

8. They tend to take a pretty dim view of humanity, attributing nasty motives and selfishness.

9. They tend to be hungry for admiration.

10. They tend to want to be center of attention.

11. They tend to aim for higher status and signs of their importance.

12. They tend to take it for granted that other people will make extra efforts to help them.

In organizational settings, one or more of the dark triad personalities have counterproductive behavior. They are evident in the notions of "toxic leadership", "snakes in suits", "bad bosses", "shark-managers". The same applies to non-leaders as well. The examples of organizational settings where high levels of dark triad traits combined with other factors such as intelligence or physical attractiveness (which often help an individual acquire positions of leadership) are also known. Dark triad traits help people "get ahead" of but not necessary "get along" with others at work (Furnham et al., 2013, p. 206). For a destructive organizational climate, bad leaders are often not enough but they need followers which "conspire" with the bad leader and particular situation. The toxic triangle is presented in figure 2. 


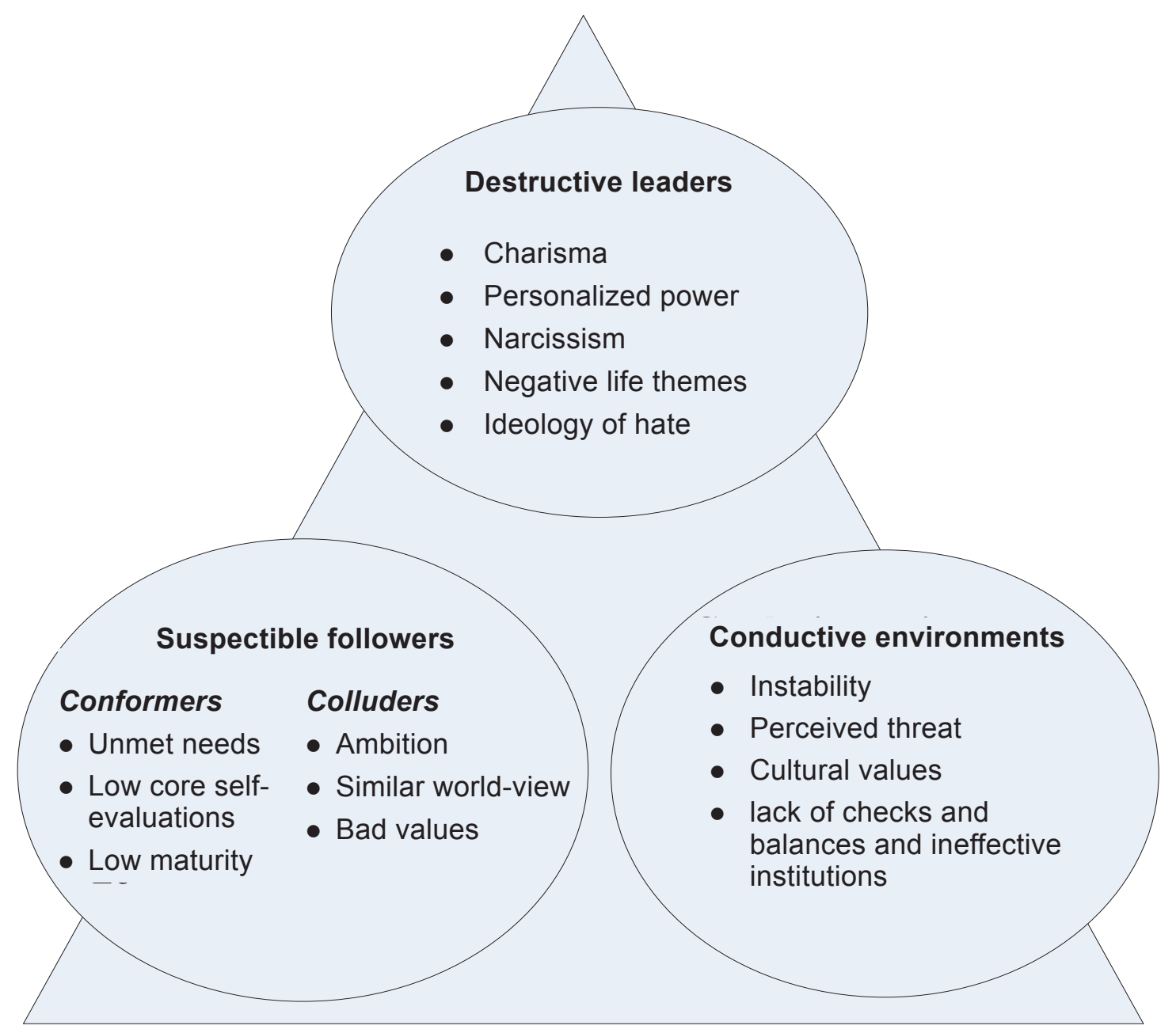

Source: Furnham (2010).

Toxic employees, as embodied by the dark triad traits, ${ }^{2}$ present problems for any company/organization, supervisors, and fellow employees. This includes disintegration of teamwork performance and of organizational effectiveness (Boddy, 2015). Because leaders unite, direct, and coordinate people to achieve a goal, destructive leaders can be extremely dangerous (in interactions with followers and conducive environment, they can even destroy organizations), so it is important to learn how those employees (managers and others) who score high on the dark triad traits behave at work, and what preventive measures to be taken. In figure 3, we present a more complex picture of the toxic triangle surrounding dysfunctional leadership and organizations where dark triad personality traits have an important place.

2 Among toxic employees traits, we may mention sadism which is included under the rubric of the Dark Tetrad (Chabrol et al., 2009), borderline disorder and status-driven risk-taking (Furnham et al., 2013). 


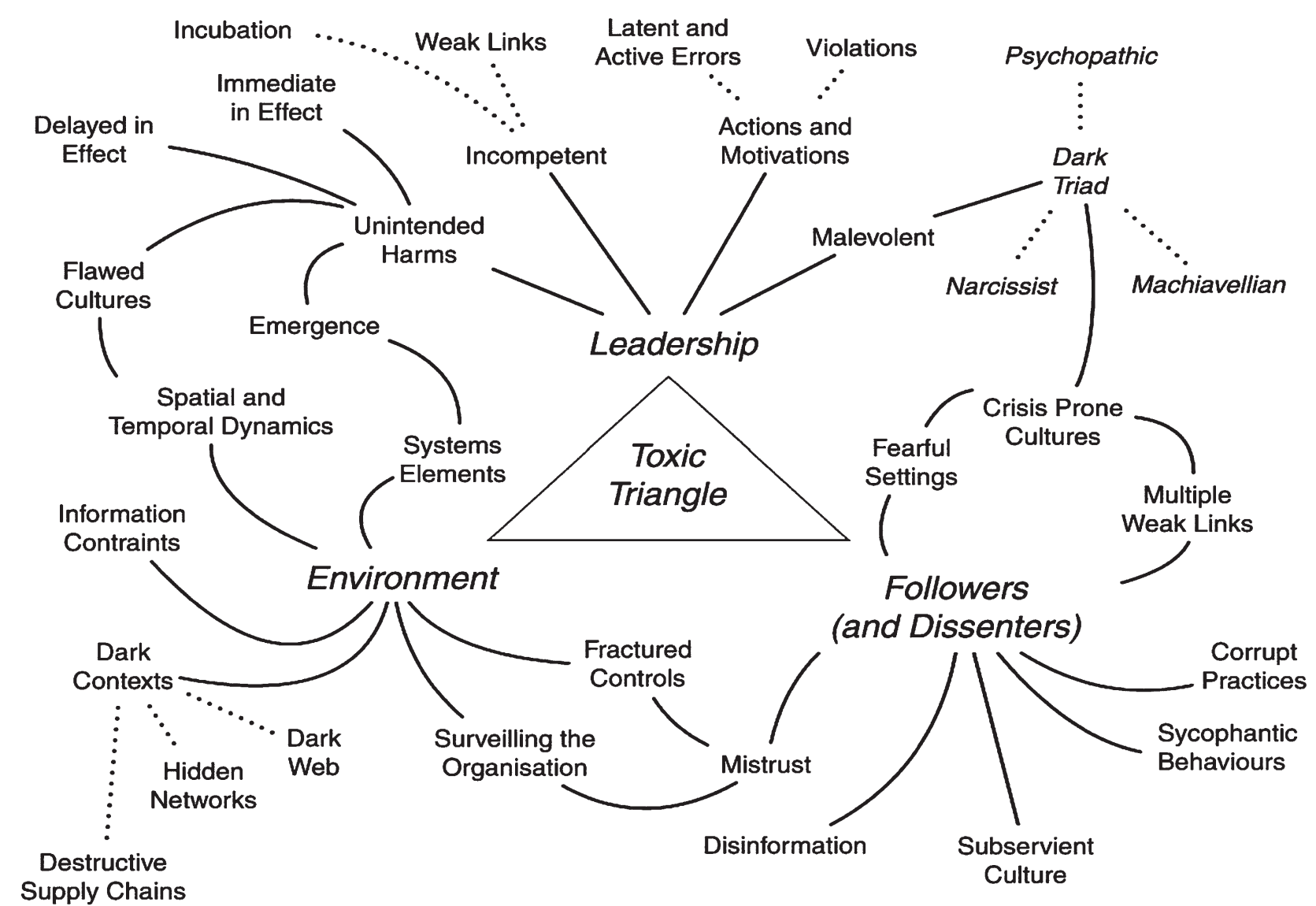

Source: Fisherbacher-Smith, 2015.

Because dark triad personalities are utterly toxic for organizational culture/climate and produce bad organizational outcomes, it is very important to make steps toward preventing the dark triad personalities and behavior especially by management/business leadership. Namely, for organizational success, it is extremely important to have management/business leadership without such pathological personalities. The empirical evidence in transition organizations and economies has shown that bad management/leadership which can be at least attributed to the dark triad personalities (Machiavellianism, narcissism, psychopathy) is responsible for bad organizational and socio-economic results. For example, in "big business" just the cases of Enron, Lehman Brothers, Worldcom, Freddie Mac, Bernie Madoff, and plenty of other multibillion dollar fraud cases have drawn the attention of the public and researchers to the dark triad traits, and negative consequences of such traits in the workplace (Jonason et al., 2015). Therefore this research has a goal to achieve the greater awareness of the dark triad organizational problem, with an emphasis on organizational measures to prevent and diminish it. The first step is the organizational diagnosis of such behavioral traits and then providing therapy against such pathological organizational behavior. This paper is a step in eliminating/ diminishing such a pathology in organizations throughout the world.

This paper aims to explore the dark triad personality traits of the management student population in Croatia, to compare them with the Canadian students of management and to propose basic measures to reduce the dark side's effects in the organizational future. The research problems are defined as follows: 
a) To identify the items from the Croatian sample that have high values in the dark management triad as compared to the Canadian sample.

b) To compare the deviant management scales (Machiavellianism, narcissism and psychopathy) between the Croatian sample $(\mathrm{N}=150)$ and the Canadian sample $(\mathrm{N}=387)$ from the research of Jones and Paulhus (2012).

c) To examine if there is a statistically significant difference in the variables of Machiavellianism, narcissism and psychopathy between male and female management students in the Croatian sample.

d) To examine possible causes of obtained results on the Croatian sample and explore what can be done to decrease evident presence of the dark side's personalities in order to avoid or diminish its future negative effects in organizations.

\section{Methodology}

Because there is little evidence on the "dark sides of business" and deviant management behavior and deviant managers values (virtues) in Croatia and other transition economies, the authors consider the topic (although interesting and for management and organizations very relevant) to be a new line of research. This work has its foundation in a sample of professional management students from the Faculty of Economics at the University of Split in Croatia - hereafter referred to as Croatian sample. The goal was to research the frequency of "dark management triad" (variables Machiavellianism, narcissism, psychopathy) on the second largest economic faculty in Croatia (nowadays the Faculty of Economics at the University of Split, which hosts almost 4500 students) which also educates future management professionals. This type of research can forecast the future economic efficiency of such human resources, and prevent the possible bad economic outcomes in different types of organizations.

\subsection{Measurement Instruments}

In order to measure the dark management personalities we used the popular measure of the Short Dark Triad. This 27-item instrument has been employed successfully by a number researchers (e.g. Arvan, 2011; Baughman et al., 2011). The short dark triad questionnaires (Jones and Paulhus, 2012) has nine items of Machiavellianism, nine items of narcissism and nine items of psychopathy. The dark triad questionnaire used a five degree Likert scale. The original questionnaire is attached in the appendix. For the purpose of the research on the Croatian population sample, the basic questionnaire was translated into Croatian. The descriptive statistics of the questionnaire on the Canadian student population $(\mathrm{N}=387)$ are presented in table 1 and table 2.

From the presented norms, it can be seen that all three variables (Machiavellianism, narcissism and psychopathy) have good reliability (Cronbach Alpha for all the three variables was between 0.77-0.80).

The dark triad measurement instruments exhibited a relatively low degree of intercorrelation, so it can be considered that the dark triad variables are rather "pure", not only conceptual but also empirical concepts. Some of the past studies suffered from measurement issues, i.e. empirical overlap; for example, subclinical psychopathy and narcissism loaded on the same factor (Furnham and Crump, 2005; Furnham and Trickey, 2011; Furnham et al., 2013, p. 202). 
Table 1 | Psychometric norms for dark triad variables

\begin{tabular}{|l|c|c|c|}
\hline & Mean & S.D. & Alpha \\
\hline Machiavellianism & 3.1 & .76 & .78 \\
\hline Narcissism & 2.8 & .88 & .77 \\
\hline Psychopathy & 2.4 & 1.0 & .80 \\
\hline
\end{tabular}

Source: Jones and Paulhus (2012)

Table 2 | Intercorrelations between the main three dark triad variables

\begin{tabular}{|l|c|c|c|}
\hline & Machiavellianism & Narcissism & Psychopathy \\
\hline Machiavellianism & -- & .23 & .37 \\
\hline Narcissism & & -- & .20 \\
\hline Psychopathy & & & -- \\
\hline
\end{tabular}

Source: Jones and Paulhus (2012)

\subsection{Data}

The measurement was conducted in April and May 2013 on the sample of $\mathrm{N}=150$ professional management students in their second year of studies at the Faculty of Economics, University of Split in Croatia. From a total of 150 student subjects, 117 were female and 33 male with age differentiation from 20-29 years.

\subsection{Procedure}

Before questionnaire application, the Dean and Vice-Dean for Pedagogy at the Faculty of Economics, University of Split were kindly asked for approval of the research during a pause between two teaching hours of Human Resource Management. Then, the students were explained the goals of the research, and they were kindly asked for their approval to be included in this research. Only students who agreed participated in the survey. The questionnaire filling was anonymous and took approximately five minutes. The data processing was conducted in the SPSS statistical package.

\section{Results and Discussion}

To deal with the first research problem, we identified high values of dark triad items in the Croatian sample. After the presentation of the descriptives (arithmetic mean and standard deviation) of each item of the dark triad measures in table 3, the results are presented in three parts: I) high value items from the variable Machiavellianism in the Croatian sample; II) high value items from the variable narcissism in the Croatian sample; and III) high value items from the variable psychopathy in the Croatian sample.

In the following text, $M$ denotes the mean, while $s$ denotes the standard deviation. 
Table 3 | Arithmetic means and standard deviations of dark triad items obtained from of the Croatian sample

\begin{tabular}{|c|c|c|}
\hline $\begin{array}{l}\text { Name of items (Items from No. 1-9 = Machiavellianism; Items from } \\
\text { No. 10-18 =narcissism; Items from No. 19-27 = psychopathy) }\end{array}$ & Mean & $\begin{array}{l}\text { Std. } \\
\text { Deviation }\end{array}$ \\
\hline 1. It's not wise to tell your secrets. & 4.220 & .703 \\
\hline 2. Generally speaking, people won't work hard unless they have to. & 3.920 & .773 \\
\hline 3. Whatever it takes, you must get the important people on your side. & 3.580 & .829 \\
\hline 4. Avoid direct conflict with others because they may be useful in the future. & 3.360 & .914 \\
\hline 5. It's wise to keep track of information that you can use against people later. & 2.940 & 1.159 \\
\hline 6. You should wait for the right time to get back at people. & 2.900 & 1.349 \\
\hline $\begin{array}{l}\text { 7. There are things you should hide from other people because they don't } \\
\text { need to know. }\end{array}$ & 4.260 & .846 \\
\hline 8. Make sure your plans benefit you, not others. & 3.560 & 1.172 \\
\hline 9. Most people can be manipulated. & 3.800 & .723 \\
\hline 10. People see me as a natural leader. & 2.960 & .776 \\
\hline 11. I hate being the center of attention. (R) & 3.400 & .897 \\
\hline 12. Many group activities tend to be dull without me. & 2.780 & 1.009 \\
\hline 13. I know that I am special because everyone keeps telling me so. & 2.800 & .919 \\
\hline 14. I like to get acquainted with important people. & 3.500 & 1.008 \\
\hline 15. I feel embarrassed if someone compliments me. (R) & 3.240 & 1.034 \\
\hline 16. I have been compared to famous people. & 2.960 & 1.152 \\
\hline 17. I am an average person. (R) & 3.460 & .924 \\
\hline 18. I insist on getting the respect I deserve. & 3.560 & .901 \\
\hline 19. I like to get revenge on authorities. & 2.620 & 1.078 \\
\hline 20. I avoid dangerous situations. (R) & 3.700 & .880 \\
\hline 21. Payback needs to be quick and nasty. & 2.400 & 1.080 \\
\hline 22. People often say I'm out of control. & 2.280 & 1.099 \\
\hline $\begin{array}{l}\text { 23. It's true that I can be mean to others. (or I enjoy having sex with people } \\
\text { I hardly know.) }\end{array}$ & 2.780 & 1.208 \\
\hline 24. People who mess with me always regret it. & 2.440 & 1.045 \\
\hline 25. I have never gotten into trouble with the law. $(R)$ & 3.800 & 1.418 \\
\hline 26. I like to pick on losers. & 2.040 & 1.284 \\
\hline 27. I'Il say anything to get what I want. & 2.640 & 1.216 \\
\hline Total $\mathrm{N}=27$ dark triad items & & \\
\hline
\end{tabular}

Note: $(\mathrm{R})=$ reversed item

Source: Research results 


\subsection{Identification of Items of the Croatian Sample that Have Higher Values in Dark Management Triad as Compared to the Canadian Sample}

I) At first glance we observed higher results on the Machiavellianism scale (items 1-9). Because the Canadian sample's mean for the variable Machiavellianism $(M=3.1$; $s=0.76)$ is a result that falls more than one standard deviation below the arithmetic mean of Machiavellianism (greater or equal to 3.86), the values of this item for Croatian sample can be considered as high. According to this criterion, the high Machiavellianism item values of the Croatian sample were:

- $\quad$ 1. It is not wise to tell your secret. $(M=4.22 ; s=0.70)$

- 2. Generally speaking, people won't work hard unless they have to. $(M=3.92$; $s=0.77)$

- 7. There are things you should hide from other people because they don't need to know. $(M=4.26 ; s=0.86)$

Based on these results, we concluded that from the nine items of the Machiavellianism variable, the Croatian students scored higher in three items. Also the item 9 "Most people can be manipulated" $(M=3.80 ; s=0.72)$ can be seen as high in the Croatian sample and is somewhat higher than the Machiavellianism mean in the Canadian sample. These results direct us to the conclusion that Croatian students scored higher in typical Machiavellianism items than Canadian students.

II) As to narcissism (items 10-18), similarly, we consider a result to be significantly higher if it falls more than one standard deviation above the Canadian sample mean $(M=2.80 ; s=0.88)$, so a significantly high $M_{\text {Narcissism }}$ should be greater or equal to 3.68 . According to this criterion, there are no "significantly" high results in any narcissism item in the Croatian sample.

III) According to the same criterion, concerning the dark triad scale of psychopathy (items 19-27), the Canadian sample scores $M=2.4 ; \mathrm{s}=1.00$, so significantly higher results in the Croatian sample should be the items where $M_{\text {psychopathy }}$ is greater or equal to 3.40. Such psychopathy items were:

- 20. I avoid dangerous situations. (R) $(M=3.70 ; s=0.88)$ - this means a question about liking dangerous situation (because this is a reversed item).

- 25. I have never gotten into trouble with the law. (R) $(M=3.80 ; s=1.42)$ - this means a question about having troubles with the law (because it is a reversed item).

Of the nine items describing psychopathy, two items of the Croatian sample scored higher.

\subsection{Comparison between the Deviant Management Scales between the Croatian and Canadian Samples}

In order to determine whether the results on the scales of Machiavellianism, narcissism and psychopathy are statistically significantly different between the Croatian and Canadian samples (table 1), we conducted a simple t-test. In table 4 we present the results for the dark triad scales on the Croatian sample which is compared with the Canadian sample. 
Table 4 | Arithmetic means and standard deviations for the variables Machiavellianism, narcissism, and psychopathy on the Croatian sample

\begin{tabular}{|l|c|c|}
\hline Variable & Mean & Std. Deviation \\
\hline Machiavellianism & 3.615 & 0.536 \\
\hline Narcissism & 3.184 & 0.455 \\
\hline Psychopathy & 2.744 & 0.592 \\
\hline
\end{tabular}

Source: Authors.

The results can be summarized as follows:

a) The Croatian sample has statistically significant higher Machiavellianism than the Canadian sample $(t=8.87 ; p<0.01)$.

b) The Croatian sample has statistically significant higher narcissism than the Canadian sample $(t=6.51 ; p<0.01)$.

c) The Croatian sample has statistically significant higher psychopathy than the Canadian sample $(t=4.85 ; p<0.01)$.

It should be noted that there are several cultural-social determinants of the Croatian sample population which are possible mediators of such results. For example, a statistically significant high result in a Machiavellianism variable can be explained in terms of increased competition because of the situation of higher unemployment in Croatia, where management students perceive that the ends are more important than the means, so if they want to succeed, they should behave in a Machiavellianism manner.

A possible explanation of the emphasized Machiavellianism values in the Croatian sample is that such behaviors are rewarded (Pastuovic, 1999), that in Croatian society successful people have dominant Machiavellianism personal traits. It should be noted that in Croatia, honesty, justice, integrity and altruism are rarely rewarded in terms of social success. Also, parents and the external environment of examined students may not internalize in their pedagogy the value model of integrity, truth, love, correct behavior, equanimity, nonviolence, integrity (ethical values), but rather the values of "you should adapt to the current situation". Also, these days, few Croats are really shocked by non-ethical and criminal behavior if they result in material wealth and social prestige. In everyday small talks, it can be heard that some Croatian people would like to have the benefits which come from unethical or even criminal ways, if only they had a chance to do so. This can be illustrated by the fact that one of the former Croatian ministers of finance stated "I would steal under certain conditions!"3 The justice system in Croatia does not function very well, and social success is measured by how much common property (social property from the former socio-economic formation) is privatized. The culture in Croatia favors fast wealth making, and Machiavellianism is a good tool to achieve that. So in a culture where the counter-normal Machiavellianism behavior is normalized, it is obvious that the Croatian sample displays somewhat higher Machiavellian values.

3 http://www.republika.eu/novost/22552/krao-bih-pod-odredenim-uvjetima-ne-sramim-se-toga 
Also, the statistically significant higher narcissism of Croatian students can be attributed to the genetic and social factors characteristics of this sample. In this work, however, we discuss only the social factors. Narcissism and the feeling of some Croatian people that they are better than others may be internalized by parents' pedagogy, and it can also be the consequence of a national narcissism legend that Croats are more capable, smarter, more beautiful, and stronger (e.g. in sport) than other nations. Narcissism could be connected with a defensive mechanism in the situation when the desired goals are not achieved. Psychologically and culturally Croats are likely to be successful, smart and rich, and the easiest way to achieve it is preferred; i.e. if it is easier to achieve it via narcissism's rationalization approach, then it would be more likely to be used in the population. According to Landes (2003), pride, self-contentment, the paradox of a superiority complex, disdain and underestimation, lack of clarity and manipulation, i.e. narcissistic behaviors, are connected with the culture of economic stagnation, so such statistically significantly higher personality traits in the Croatian sample can be a result of the longterm stagnation of Croatian enterprises and economy.

Statistically significantly higher psychopathy of the Croatian sample can be explained by the combination of genetic and social factors of this sample, and can be partially attributed to the higher Machiavellianism and narcissism, because the concepts of the dark triad are not totally pure and they are somehow overlapping (see table 2). The great deal of psychopathy has genetic reasons (Pastuovic, 1999), which are not discussed in this work. ${ }^{4}$

\subsection{Difference in the Variables of Machiavellianism, Narcissism and Psychopathy between Male and Female management students in the Croatian Sample}

To explore if there is a statistically significant difference between research variables between female and male subjects in the Croatian sample, we performed an ANOVA test whose results are presented in table 5.

The results suggest that there is a statistically significant difference between male and female subjects $(F=9.171 ; p=0.003)$ in the Machiavellianism variable, and in the psychopathy variable $(F=10.743 ; p=0.001)$. No statistically significant difference was found in the variable of narcissism.

Male students scored statistically significantly higher in Machiavellianism $\left(M_{\text {Machiavellianism }}=3.84, s=0.47\right)$ as compared to female students $\left(M_{\text {Machiavellianism }}=3.54\right.$; $s=0.54)$. Male students also scored statistically significantly higher in psychopathy $\left(M_{\text {psychopathy }}=3.03 ; s=0.61\right)$ when compared to females $\left(M_{\text {psychopathy }}=2.66 ; s=0.56\right)$. Such results are consistent with past literature (Furnham et al., 2013), which suggest that male managers are prone to Machiavellianism and psychopathological behavior.

4 A possible genetic marker of psychopathy is HLA-B27 (Gattaz, 1981, according to Pastuović, 1999., p. 223). Men have statistically higher average results on the psychoticism scale, which indicates a hormonal basis of psychopathy. Other comparative research on kin and non-kin demonstrates a high degree of congenital and inheritance of psychopathy. Psychopaths have difficultly to learn values, and also have a genetic predisposition for antisocial behavior. Psychopaths have a congenital need for strong stimulii, and the best way to satisfy it is by making damage to other persons (Pastuović, 1999., p. 223). 
Table 5 | Differences in the variables Machiavellianism, narcissism and psychopathy between male and female students in Croatian sample (ANOVA)

\begin{tabular}{|l|l|c|c|c|c|c|}
\hline & & $\begin{array}{c}\text { Sum of } \\
\text { Squares }\end{array}$ & \multicolumn{1}{|c|}{$\mathbf{d f}$} & $\begin{array}{c}\text { Mean } \\
\text { Square }\end{array}$ & F & Sig. \\
\hline \multirow{3}{*}{ MACHIAVELLIANISM } & Between Groups & 2.499 & 1 & 2.499 & 9.170 & .003 \\
\cline { 2 - 7 } & Within Groups & 40.332 & 148 & .273 & & \\
\cline { 2 - 7 } & Total & 42.830 & 149 & & & \\
\hline \multirow{3}{*}{ NARCISSISM } & Between Groups & .142 & 1 & .142 & .685 & .409 \\
\hline & Within Groups & 30.718 & 148 & .208 & & \\
\hline & Total & 30.860 & 149 & & & \\
\hline PSYCHOPATHY & Between Groups & 3.457 & 1 & 3.457 & 10.473 & .001 \\
\hline & Within Groups & 48.858 & 148 & .330 & & \\
\hline & Total & 52,315 & 149 & & & \\
\hline
\end{tabular}

Source: Authors.

\subsection{Measures for Reducing the Dark Triad Organizational Threat}

While the Croatian sample had statistically significant higher dark triad values than the Canadian sample, it is clear that no one is immune to dark triad effects. So, it is important to find ways to reduce and avoid the dark side's effects in organizations. The basic approach could involve (Alvesson and Spicer, 2012; Bogdanovic, 2014; Culham, 2013; Fry and Altman, 2013; Hartel et al., 2014; O’Boyle et al., 2012, Yatzeck, 2012):

1. Recruitment and selection. When some candidates lack concern over ethics, it indicates a manipulative personality (Machiavellianism). When some candidates are over-confident, over-self-promoting or entitled, this is an indication of a narcissistic personality, and if some of candidates overuse the impression management tactics it can be an indication of a psychopathic personality.

2. Workplace conditions. The organizational conditions that may "bring out" the dark triad in current employees include e.g. "pitting" of teams or departments against each other, unequal treatment, lack of structure, understood corporate values, deliberate management manipulation.

3. Ethics education and promotion of spirituality management. Introducing servant leadership with human values of truth, doing right, love, peace and nonviolence promotes an ethical organizational climate/culture.

4. Employee dark triad awareness and behavior against dark triad personalities. When the threat of dark triad persons in organization is obvious and very real, employees should not confide things (either in oral or written form) or trust without verifying; they should be careful of charming smiles, and be alarmed by unethical behavior or violent behavior from higher management or board of an organization. 


\section{Limitations of the Research and Proposals for Further Research}

The main limitation of the conducted research is a limited sample with a relatively low number of subjects $(\mathrm{N}=150)$, which was also conducted at only one Croatian University. Another limitation can be the language differences between the English and Croatian versions of the questionnaires, although the translation was conducted in "the spirit of language" (e.g. item 5 was translated as "It's true that I can be evil to others" because the language can represent different social norms). Also e.g. the term "losers" has a different denotative meaning in "Anglo-Saxon" society and culture than in Croatian culture (in former Yugoslavia under socialism, such a term was practically unknown and thus it still does not have such a negative connotation in Croatia as it has elsewhere; rather, it means something closer to be unlucky). The language differences could make small differences in the results. For these reasons, in high-quality psychometric research, there is a need to standardize questionnaires that are supposed to be valid in a specific cultural surrounding. Another limitation is the comparison with the Canadian sample, which is a totally different culture than the Croatian one. Therefore, for Croatian norms for subclinical Machiavellianism, narcissism and psychopathy to be obtained, this research should be done on a larger sample. We suggest that further research on the dark management triad should be conducted in other Croatian regions, because Croatia consists of five different geographic regions which are culturally and mentality somewhat different (Ozimec, 2001), so different results in dark triad traits can be expected. Because the research of the dark management triad in transition economies and organizations is in a very early phase, there is quite a large space for further research in this management area. For example, the research of dark management triad in the countries which resulted from the former Yugoslavia (Slovenia, Croatia, Bosnia and Herzegovina, Serbia, Montenegro, Kosovo and Macedonia) is promising. In order to more completely understand the deviant workplace behavior of dark triad personalities, there is need to apply a multi-paradigmatic approach, e.g. the Burell and Morgan's framework (Samnani, 2013). For a deeper understanding of the deviant workplace behavior, the following approaches can be applied:

a) Functionalist approach - where the emphasis is on predicting which interpersonal characteristic contributes to the deviant organizational situation, i.e. discovering of regularities and causal relationships that exist between the variables of interest.

b) Interpretivism approach - which emphasizes understanding of employees' feeling and meanings about toxic employees and deviant workplace/organizational situations.

c) Critical management theory approach - which emphasizes the role of power and alienation in institutions, i.e. the focus of research is on broader issues of power within institutions, which may be stimulus for workplace/organization deviations. So deviant workplace/organizational situations can be researched as the result of authority and discipline which normalizes such a situation in the eyes of society and the employees.

d) Postmodernic perspective - emphasizes the presence of multiple "truths", need for emancipation and well-being of employees and the focus of research is on the management practices that produce organizational obedience through the simple 
exertion of power, control and surveillance. Postmodernistic research is focused less on performance enhancement but more on emancipation and well-being of employees.

Therefore seeking to understand the deviant workplace/organizational situation should include multi-paradigmatic approaches of organizational research.

\section{Conclusion}

This research has the following findings:

- $\quad$ Some dark triad items of the Croatian sample were found to be much higher compared to the Canadian sample.

- All three dark triad scales (Machiavellianism, narcissism, psychopathy) of the Croatian sample were statistically significantly higher than in the Canadian sample.

- In the Croatian sample, we found statistically significant differences between male and female subjects in Machiavellianism and psychopathy, in the direction of higher values of male students, but not in the scale of narcissism.

- The cause of statistically significant higher results of dark triad variables in the Croatian sample in comparison with the Canadian sample can be explained by cultural and social determinants of the examined populations. Organization should be aware of dark triad personalities and decrease the dark side's effects by the proposed activities.

Dark triad persons are very dangerous (especially managers/business leaders), because in their organizational presence, a favorable ethical climate and culture is not possible. Therefore, organizations have every responsibility to avoid dark triad negative effects. The practical implications of this paper are in raising awareness and stimulating thinking by practicing managers around the role that "dark triad" personality traits of engaged human resources can create potential for organizational crises, and to make preventive and responsive actions to manage the "toxic triad" threat.

\section{References}

Alvesson, M., \& Spicer, A. (2012). A Stupidity-Based Theory of Organizations. Journal of Management Studies, 49(7), 1194-1220.

Arvan, M. (2013). Bad news for conservatives? Moral judgments and the Dark Triad personality traits: A correlational study. Neuroethics, 6(2), 307-318.

Baughman, H. M., Dearing, S., Giammarco, E., \& Vernon, P. A. (2011). Relationships between bullying behaviours and the Dark Triad. Personality and Individual Differences, 52, 571-575.

Black, P. J. (2013). The Dark Triad and interpersonal assessment of vulnerability: Cues used and accuracy. Master thesis. Faculty of graduate study in Psychology University of British Columbia.

Boddy, C. R. (2015). Psychopathic leadership a case study of a corporate psychopath CEO. Journal of Business Ethics, 1-16.

Bogdanovic, M. (2014). By spirituality management against stupidity management in a function of accelerated development. 3rd International Scientific Symposium Economy of Eastern Croatia - Vision and Growth, Osijek 22nd - 24th May 2014, Croatia: 572-593. 
Bradlee, P. M., \& Emmons, R. A. (1992). Locating narcissism within the interpersonal circumplex and the Five-Factor model. Personality and Individual Differences, 13(7), 821- 830.

Chabrol, H., van Leeuwen, N., Rodgers, R., \& Séjourné, N. (2009). Contributions of psychopathic, narcissistic, Machiavellian, and sadistic personality traits to juvenile delinquency. Personality and Individual Differences, 47(7), 734-739.

Culham, T. E. (2013). Ethics Education of Business Leaders: Emotional Intelligence, Virtues, and Contemplative Learning (Transforming Education for the Future). Charlotte: Information Age Publishing, Inc.

Einarsen, S., Aasland, M. S., \& Skogstad, A. (2007). Destructive leadership behaviour: A definition and conceptual model. The Leadership Quarterly, 18(3), 207-216.

Fischbacher-Smith, D. (2015). The enemy has passed through the gate: Insider threats, the dark triad, and challenges around security. Journal of Organizational Effectiveness: People and Performance, 2(2), 134-156.

Fry, L. W., \& Altman, Y. (2013). Spiritual Leadership in Action: The CEL Story Achieving Extraordinary Results Through Ordinary People. (Advances in Workplace Spirituality: Theory, Research, and Practice). Charlotte: Information Age Publishing Inc.

Furnham, A. (2010). The Elephant in Boardroom: The Causes of Leadership Derailment. Basingstoke: Palgrave Macmillan.

Furnham, A., Richards, R.C, \& Paulhus, D. L. (2013). The Dark Triad of Personality: A 10 Year Review. Social and Personality Psychology Compass, 7(3), 199-216.

Hartel, C. E. J. et al. (2014). Developing Ethical Leaders: A Servant Leadership Approach. In L. E. Sekerka (Ed.), Ethics Training in Action: An Examination of Issues, Techniques, and Development (pp. 271-291). Charlotte: Information Age Publishing, Inc.

Jonason, P. K., Slomski, S., \& Partyka, J. (2012). The Dark Triad at work: How toxic employees get their way. Personality and Individual Differences, 52, 449-453.

Jonason, P. K., Wee, S., \& Li, N.P. (2015). Competition, autonomy, and prestige: Mechanisms through which the Dark Triad predict job satisfaction, Personality and Individual Differences, 72, 112-116.

Jones, D. N., \& Paulhus, D. L. (2012). Introducing the Short Dark Triad (SD3): A brief measure of dark personalities. Journal of Research in Personality, under revision.

Landes, D. S. (2003). Bogatstvo i siromastvo naroda: Zasto su neki tako bogati, a neki tako siromasni. [Wealth and poverty of the nations: Why some are so rich and some so poor?]. Zagreb: Masmedia.

Lucic, M. (2013). Istina je najvaznija: Intervju s Jackom Hawleyem. [Truth is the most important: Interview with Jack Hawley], qLife, 5(2), 45-58.

Malnick, E. (2013). Why your boss could easily be a psychopath. The Telegraph. Retrieved July 28, 2013, from http://www.telegraph.co.uk/newstopics/howaboutthat/9828914/ Why-your-boss-could-easily-be-a-psychopath-html.

O’Boyle, E. H. et al. (2012). A Meta-Analysis of the Dark Triad and Work Behavior: A Social Exchange Perspective. Journal of Applied Psychology, 97(3), 557-579.

O'Boyle, E. H. et al. (2011). The relation between emotional intelligence and job performance: A meta-analysis. Journal of Organizational Behavior, 32(5), 788-818.

Ozimec, S. (2001). Nasi mentaliteti. [Our mentality]. Varazdinske Topice: Tonimir. Bibilioteka posebna izdanja.

Pastuovic, N. (1999). Edukologija: integralna znanost o sustavu odgoja i obrazovanja [Educology: the integral science about the education system]. Zagreb: Znamen. 
Paulhus, D. L., \& Jones, D. N. (2011). Introducing a short measure of the Dark Triad. Poster presented at the meeting of the Society for Personality and Social Psychology, San Antonio.

Paulhus, D. L., \& Williams, K. M. (2002). The Dark Triad of personality: Narcissism, Machiavellianism and psychopathy. Journal of Research in Personality, 36(6), 556-563.

Plumridge, N. (2013). The Dark Triad. Retrieded July 13, 2014 from http://psychminds.com/ the-dark-triad/.

Samnani, A. (2013). Embracing New directions in Workplace Bullying Research: A Paradigm Approach. Journal of Management Inquiry, 22(26), 26-36.

Yatzeck, E. (2012). Beware the Dark Triad: Your Worst Change Management Nightmare. Pragmatic Agilist. Retrieved July 28, 2013 from http://pagilista.blogspot.ae/2012/12/ beware-dark-triad-your-worst-change.html.

Zuroff, D. C., Fournier, M. A., Patall, E. A., \& Leybman, M. J. (2010). Steps toward an evolutionary personality psychology: Individual differences in social rank domain. Canadian Psychology, 51(1), 58-66.

\section{Authors}

\section{Mario Bogdanovic, Ph.D.}

Faculty of Economics, University of Split

Assistant Professor, Senior Research Associate

Management Department

Cvite Fiskovica 5, 21.000 Split, Croatia

mbogdan2011@gmail.com

\section{Domagoj Cingula}

Ph.D. student

Varazdin Development and Entrepreneurship Agency, Croatia

dcingula@esd-conference.com 


\section{APPENDIX}

\section{SD3 - 27 items}

\section{Machiavellianism subscale}

1. It's not wise to tell your secrets; 2 . Generally speaking, people won't work hard unless they have to; 3 . Whatever it takes, you must get the important people on your side; 4. Avoid direct conflict with others because they may be useful in the future; 5 . It's wise to keep track of information that you can use against people later; 6 . You should wait for the right time to get back at people; 7 . There are things you should hide from other people because they don't need to know; 8. Make sure your plans benefit you, not others; 9. Most people can be manipulated.

\section{Narcissism subscale}

1. People see me as a natural leader; I hate being the center of attention. (R); 2. Many group activities tend to be dull without me; 3 . I know that I am special because everyone keeps telling me so; 4. I like to get acquainted with important people; 5. I feel embarrassed if someone compliments me. (R); 6. I have been compared to famous people; 7. I am an average person. (R); 8. I insist on getting the respect I deserve.

\section{Psychopathy subscale}

1. I like to get revenge on authorities; 2. I avoid dangerous situations. (R); 3. Payback needs to be quick and nasty; 4. People often say I'm out of control; 5. It's true that I can be mean to others. (or I enjoy having sex with people I hardly know.); 6. People who mess with me always regret it; 7. I have never gotten into trouble with the law. (R); 8. I like to pick on losers; 9. I'll say anything to get what I want. 